
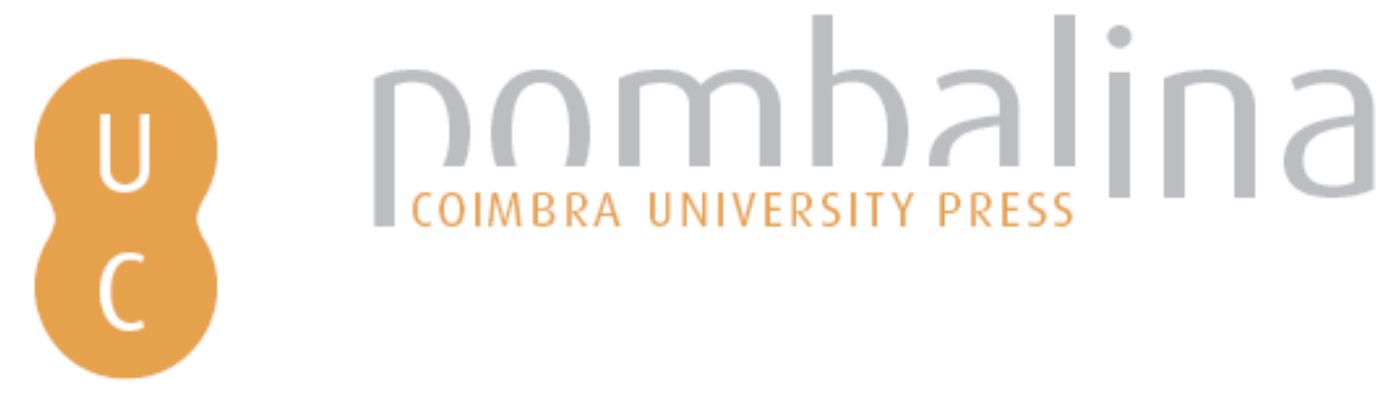

\title{
Das Guerras Samnitas ao controlo da Itália
}

\author{
Autor(es): De Man, Adriaan
}

Publicado por: Imprensa da Universidade de Coimbra

URL

persistente: URI:http://hdl.handle.net/10316.2/36914

DOI: $\quad$ DOI:http://dx.doi.org/10.14195/978-989-26-0954-6_5.2

Accessed : $\quad$ 26-Apr-2023 10:42:00

A navegação consulta e descarregamento dos títulos inseridos nas Bibliotecas Digitais UC Digitalis, UC Pombalina e UC Impactum, pressupõem a aceitação plena e sem reservas dos Termos e Condições de Uso destas Bibliotecas Digitais, disponíveis em https://digitalis.uc.pt/pt-pt/termos.

Conforme exposto nos referidos Termos e Condições de Uso, o descarregamento de títulos de acesso restrito requer uma licença válida de autorização devendo o utilizador aceder ao(s) documento(s) a partir de um endereço de IP da instituição detentora da supramencionada licença.

Ao utilizador é apenas permitido o descarregamento para uso pessoal, pelo que o emprego do(s) título(s) descarregado(s) para outro fim, designadamente comercial, carece de autorização do respetivo autor ou editor da obra.

Na medida em que todas as obras da UC Digitalis se encontram protegidas pelo Código do Direito de Autor e Direitos Conexos e demais legislação aplicável, toda a cópia, parcial ou total, deste documento, nos casos em que é legalmente admitida, deverá conter ou fazer-se acompanhar por este aviso.

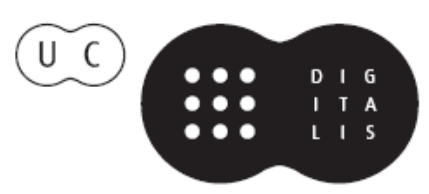


JOSÉ LUÍS BRANDÃO FRANCISCO DE OLIVEIRA (COORD.)

IMPRENSA DA

UNIVERSIDADE

DE COIMBRA

COIMBRA

UNIVERSITY

PRESS
HISTÓRIA DE
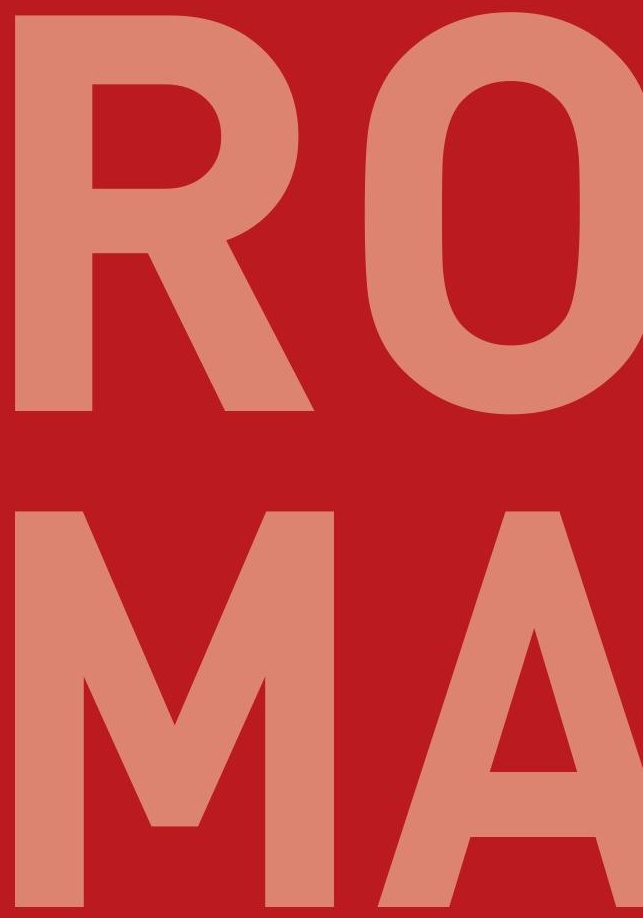

ANTIGA

VOLUME I

DAS ORIGENS À

MORTE DE CÉSAR 


\subsection{DAS GUERRAS SAMNITAS}

\section{AOCONTROLO DA ITÁLIA}

Adriaan De Man

Universidade Nova de Lisboa

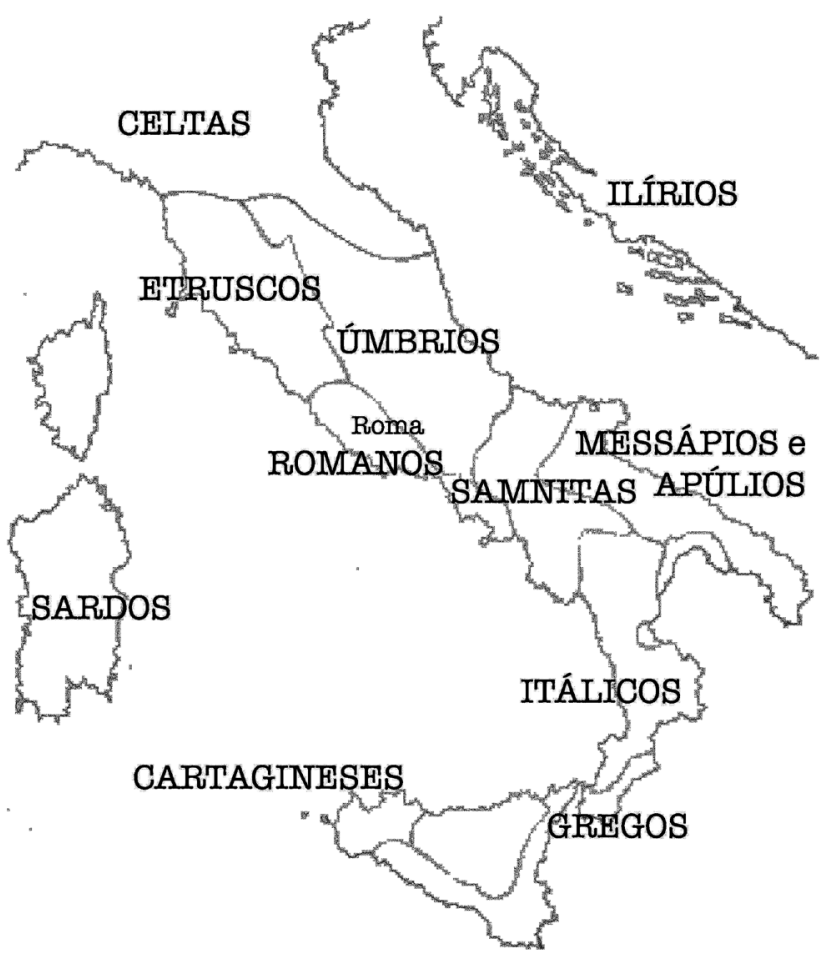

Fig. 1. Povos de Itália (400 a.C.) - por Fábio Mordomo 
Sumário. Tensão entre as pretensões expansionistas romanas e os habitantes das montanhas do centro itálico. Conflitos regionais constantes e afirmação hegemónica: as três guerras Samnitas. Fim da Liga Latina. Guerra Pírrica e controlo de Itália. Resultados da conquista da Itália

\section{Os Samnitas}

Organizados em quatro tribos, os Samnitas ocupavam a zona montanhosa dos Apeninos centrais e meridionais. Neste vasto território acidentado, os Caracenos e os Pentros, no Centro e Norte, viviam numa lata confederação político-militar com os Caudinos e Hirpinos, cujas fronteiras, igualmente latas, acompanhavam os territórios gregos da baía de Nápoles. Salvo os Messápios, mais a sul e na costa adriática, todos os povos da região falariam provavelmente dialetos de raiz osca, aparentados à língua samnita, isto quando não existiam laços mais diretos. De facto, destacam-se importantes assentamentos entre as montanhas e a costa, pelo menos desde o século $\mathrm{V}$ precoce, de comunidades samnitas que buscavam zonas mais férteis, lidando em simultâneo com pressões demográficas internas que impeliam à migração. O território samnita em si era, tal como hoje, uma região árida com reduzidas potencialidades agrícolas, onde um vetor principal da economia consistia na pastorícia transumante, e onde escasseavam grandes investimentos urbanos. A arqueologia vai comprovando a diminuta presença de bens de importação mesmo nos sítios dominantes, e as emissões monetárias são uma raridade, além de corresponderem a um ou dois anos da guerra tardia, nos quais houve episódica cunhagem com indicação de Safinim, o nome osco de Sâmnio ${ }^{1}$. Do ponto de vista organizacional, portanto, não se tratava de uma sociedade com cidades-Estado, como eram as dos seus vizinhos romanos, gregos e etruscos. À moda celta, a sua estrutura fundamental consistia numa unidade tribal que, na língua osca, se designava por touto, mas por outro lado é interessante

\footnotetext{
${ }^{1}$ Salmon 2010 75-76.
} 
constatar que esta unidade era governada por um governo republicano muito incipiente, através de um magistrado eleito todos os anos - o medix tuticus, transponível para Latim como iudex publicus. O cargo e as suas variantes surgem documentados nalguma epigrafia osca prévia à Guerra Social $^{2}$, assim como numa citação descontextualizada dos Anais de Énio (Ann. 298)3 e em Lívio (26.6.13). As cidades não representavam porém civitates no sentido romano, entendidas como unidades cívicas centralizadoras de um território, e como aglomerações comunitárias distintivas. Até à sua integração final, e mesmo depois, Sâmnio continuou a funcionar de acordo com aquela ancestral unidade itálica a que se chamou pagus, num esquema que se mantinha fundamentalmente pré-urbano. Seriam em particular as aristocracias "pagãs" a perder proeminência económica e social, culminando numa situação estrutural de longa duração no seio das várias microeconomias itálicas. Três séculos após as primeiras guerras entre Romanos e Samnitas, registar-se-ia ainda um mínimo muito notório de famílias senatoriais provenientes destas mesmas áreas ${ }^{4}$. A rusticidade dos Samnitas, montani atque agrestes (Liv. 9.13.7), perduraria no imaginário romano, mesmo já em cronologia imperial5.

\section{A primeira Guerra Samnita (343-341) e a Guerra Latina (340-338)}

A dinâmica expansionista romana, conformada no imediato na ocupação de Veios, viria a provocar em pouco tempo um contacto direto com as tribos samnitas. Lívio (7.19.4) e Diodoro (16.45.8) mencionam um tratado de 354 a.C. do qual nada se conhece, mas que tem sido interpretado como uma definição de territórios, provavelmente tendo o rio Líris, que atravessa as terras dos Marsos e dos Volscos, como orientador. Este pacto seria, no entanto, de curta duração.

\footnotetext{
2 Buck 2005 239; 241; 247; 250.

3 Skutsch 198595.

4 Torelli 2000 10-11.

5 Mahé-Simon 2008 73-75.
} 
Se os termos de 354 giravam realmente em torno do Líris, o pretexto para a abertura de hostilidades deu-se na Campânia, a sul do rio e portanto na zona de influência de Sâmnio. Quando Teano, cidade-charneira dos Sidicinos, foi assaltada pelos Samnitas, procurou auxílio junto de Cápua, e esta, por seu turno, viu-se também ameaçada. Seguindo o relato liviano, os apelos iniciais a Roma não surtiram efeito, mas por fim o dramatismo dos embaixadores de Cápua convenceu o senado de que, apesar do acordo, seria necessário prestar assistência militar contra os Samnitas. Em menos de dois anos, terminaria o primeiro conjunto de embates com este povo, culminando numa vitória romana e num acordo de paz. Neste contexto, a Guerra Latina representa um segundo conflito regional, com justificações particulares mas, apesar até da troca de contendores, revela-se inseparável das permanentes altercações com os povos montanheiros, cuja inquietação primeira, no fundo, era partilhada com os que habitavam as terras baixas. Ela pode resumir-se ao crescimento do poder de Roma, e nas justificadas preocupações por parte dos restantes povos latinos, que conduziram à discórdia. De novo, os Samnitas atacaram os Sidicinos, cujos aliados latinos retaliaram, e a alegação nominal para a entrada de Roma no conflito, desta feita, radicaria num pedido samnita para que os Romanos controlassem os seus próprios vizinhos. O resultado final da guerra consistiu na incorporação de diversas cidades latinas no Estado Romano, assim terminando com a Liga Latina ${ }^{6}$, e no enfraquecimento político de duas outras, Preneste e Tibur, que se manteriam aliadas, fornecendo tropas.

O desaparecimento da liga de Estados latinos não acarretou uma desagregação substantiva dos laços de solidariedade regionais. Pelo contrário, Roma efetivamente integrou os Estados latinos, fomentando até a ideia de um passado comum, em particular uma origem troiana ou albalonguense, dependendo da tradição. A promoção do festival latino anual, no Monte Albano, reflete um respeito pelos ancestrais costumes, e representa acima de tudo um mecanismo político de integração. Do ponto de vista legal, algumas comunidades do Lácio receberam uma cidadania limitada, a civitas sine suffragio, retirando dela reais benefícios, até em matéria de

\footnotetext{
${ }^{6}$ Sobre a Liga Latina, vide atrás Brandão, cap. 3 §, e Faversani e Joly, cap. 5.1 §1.
} 
direito privado, acarretando por outro lado obrigações militares muito onerosas, cujo beneficiário principal era Roma. Em simultâneo, assistiu-se a uma série de novas fundações coloniais.

\section{A Segunda Guerra Samnita (326-304)}

Fica pouco claro até que ponto esta implantação territorial terá provocado intencionalmente o segundo grande conflito com os Samnitas. É um facto que a colónia de Fregelas em particular, na margem esquerda do Líris e controlando um importante acesso aos Apeninos centrais, fazia parte de uma estratégia inquietante para o lado samnita. As primeiras agressões partiram, no entanto, do terceiro grande ator itálico, através de uma série de assaltos a territórios na Campânia, conduzidos a partir da cidade de Palépolis, envolvendo rapidamente as demais, como Nápoles e a poderosa Tarento. Uma ligação inicial clara com os Samnitas é indestrinçável, dado que as cidades gregas eram habitadas por importantes comunidades falantes de osco. Ainda que muito transformadas desde aquelas migrações antigas, a solidariedade com os seus primos distantes era naturalmente maior do que com Romanos ou mesmo com as elites gregas locais, e não surpreende a rápida entrada em cena de contingentes samnitas, em defesa dos centros gregos. Na sequência de rejeições às pretensões romanas, o início da guerra é sintomático dos novos desafios que a expansão romana acarretava. Logo no fim de 327, Quinto Publílio Filão torna-se procônsul por decisão do senado e do povo, figura necessária devido a operações militares cada vez mais distantes. Em si, a prorrogação, e a subsequente promagistratura, tem o fundamento lógico da não interrupção das campanhas de um exército consular, mesmo perante a eleição dos dois novos cônsules em Roma. De forma análoga, o pretorado também evoluiria, como única magistratura revestida de império em Roma, na ausência dos cônsules 7 . Do cerco de Filão a Palépolis e Nápoles, esta retirou um acordo de rendição muito favorável e duradouro,

\footnotetext{
7 Bergk 201168.
} 
o que perturbou a posição samnita, por uma opulenta cidade comercial entrar na esfera romana ${ }^{8}$. Lúcio Cornélio Lêntulo, o outro cônsul de 327, dirigiu um segundo exército contra o território samnita. Recusadas as condições diplomáticas romanas, dar-se-ia início a cinco anos de campanhas periódicas nas montanhas do centro itálico.

A primeira fase da guerra terminou em 321 com uma derrota romana nas Forcas Caudinas, próximo de Benevento. Através de um estratagema, Gaio (ou Gávio) Pôncio convenceu o comando romano de que o seu exército estaria a cercar a cidade de Lucéria. O caminho mais direto, através de dois desfiladeiros separados por um espaço aberto, era favorável à armadilha. Quando os Romanos se deram conta da obstrução do segundo desfiladeiro, encontravam-se já encurralados pelos Samnitas, que tinham assumido posição no primeiro, e que portanto estavam em controlo total. Não se decidindo sobre o rumo a tomar, foi requerido o conselho de Herénio, pai de Pôncio, que apresentou duas alternativas, uma primeira em que os Romanos seriam libertados sem condições, ganhando-se a sua amizade, e uma segunda em que seriam chacinados, com obtenção de uma vitória robusta. Pôncio, porém, preferiu outro caminho, humilhando publicamente os cônsules e os soldados, mas libertando o exército e estabelecendo um acordo de paz, o que a longo prazo viria a revelar-se contraproducente. Esta opção viria a alimentar múltiplos exempla livianos ${ }^{9}$, nos quais Cáudio surge como lição prática para os Romanos.

Entre 321 e 317, não houve combates, e durante a paz caudina ambos os lados reforçaram as suas posições, conscientes da situação temporária. A tomada samnita de Fregelas em 320 não foi um sucesso militar, mas terá feito parte dos termos de paz no ano precedente. As hostilidades foram retomadas quatro anos após a derrota caudina, e por iniciativa samnita, que consistiu no avanço de um grande exército, ao qual Roma contrapôs as suas tropas sob comando de Quinto Fábio Máximo Ruliano, eleito ditador. A batalha principal deu-se em Láutulas, sobre o mesmo caminho para a Campânia onde também a futura via Ápia viria a passar, num estreito

\footnotetext{
8 Harris 1985181.

9 Chaplin 200047.
} 
terreno entre mar e serra. Quinto Áulio Cerretano, magister equitum, caiu ao lado de muitos outros nesta tremenda derrota romana, que abriu os campos do Lácio à invasão, e que causou revoltas e volte-faces das pequenas cidades volscas e auruncas que se viam agora sob pressão samnita. A sua recaptura romana, ao longo dos anos seguintes, envolveu execuções públicas e outros ajustes de contas com fações consideradas pró-samnitas. Também na Campânia, Cápua foi palco de uma tentativa de sair da esfera romana, resolvida em última instância com o suicídio dos responsáveis, e com a normalização das relações. Nesta fase da guerra, porém, os combates em torno das cidades tornam-se por vezes muito violentos, com sucessivos massacres de guarnições, como em Lucéria e Clúvia.

Muito revelador da energia romana é a abertura de uma nova frente de batalha na Etrúria, entre 311 e 308, isto é, em plena guerra samnita. Apesar das justificações de Lívio, parece improvável que algumas cidades etruscas estivessem realmente interessadas num conflito com Roma, tendo problemas de sobra com os Gauleses a Norte. Encontrar-se-ia uma explicação alternativa à agressão etrusca na vontade de afirmação das novas elites romanas, e a condução simultânea de operações provaria um excecional vigor e autoconfiança do Estado. A longa Segunda Guerra Samnita assistiu a alterações estruturais nos dois exércitos consulares, o que se constata, por exemplo, na generalização de acampamentos de inverno, mantendo os cidadãos-soldados mobilizados durante mais tempo ${ }^{10}$. Outro indicador claro é a súbita multiplicação de tribunos militares, de seis em 362 para dezasseis em 311'11, o que faz sentido numa duplicação das legiões, e num aumento de três para quatro tribunos por legião. Do ponto de vista organizacional, a transição é já referencial: sessenta centúrias, formando trinta manípulos, entre hastati, principes e triarii, o que equivale à renúncia completa da falange. Uma antiga convicção atribuía a organização em manípulos, assim como a utilização do pilum e scutum, a uma inspiração samnita. Mas independentemente de sucessivas adaptações no seguimento de 326, é preciso recordar que a estrutura militar romana não tinha ficado

\footnotetext{
10 Rosenstein 200431.

11 Forsythe 201137.
} 
estática. Nos cento e cinquenta anos que medeiam 415 e 265, apenas em treze não se registam confrontos ${ }^{12}$, evidenciando-se um longo padrão de campanhas anuais, que era bem prévio à grande guerra samnita.

\section{Do fim da Segunda à Terceira Guerra Samnita (298-290)}

O fim da Segunda Guerra Samnita consistiu num rápido e simultâneo avanço romano em território dos Samnitas Pentros, dos Hérnicos e dos Équos, ao longo dos anos 306 a 30413. A estas conquistas seguir-se-iam outras a um ritmo acelerado, cujo desfecho convincente impeliu outros povos, até então hostis a Roma, a estabelecer alianças. E assim o século IV terminaria com a humilhação completa de Sâmnio e dos seus aliados. Impossível de ser efetivamente ocupada, a região manteve-se controlada mas autónoma, condição que em pouco tempo acabaria por redundar num terceiro conflito de grandes dimensões. Lívio (10.11.12-12.3) oferece a justificação habitual: Roma pretendeu assistir um povo inocente sob ataque, neste caso os Lucanos, e os seus feciais foram ofendidos por mensageiros samnitas. Na realidade, o reacendimento das hostilidades em 298 insere-se num processo expansionista romano, que no interlúdio após 304 não tinha ficado interrompido. Nesses seis anos, a Etrúria e a Úmbria foram palco de agressivas campanhas de afirmação, e os Équos e os Marsos ressentiam a imparável instalação de colónias, causa de tensões no vale do Líris e regiões próximas. Quanto à Lucânia, era o único território adjacente ao dos Samnitas que em 298 não tinha ligações formais com Roma. Terá sido essa a circunstância que levou aos avanços samnitas, inicialmente em termos amistáveis e, perante a rejeição, com uma incursão militar que viabilizou a intromissão romana. Restava aos Samnitas encontrar coligados mais distantes, como os Etruscos e os Umbros, e até algumas tribos gaulesas, que em conjunto formavam uma heterogénea e improvável, mas poderosa aliança antirromana. Os anos de 297 e 296 foram portanto de grande alarme, com

\footnotetext{
12 Oakley 1993 15-16.

13 Forsythe 2005310.
} 
mobilizações de considerável alcance, como o recrutamento de libertos e a reeleição dos cônsules Quinto Fábio Máximo Ruliano e Públio Décio Mure. A estratégia romana de enfrentar o inimigo combinado com o grosso das forças, enquanto unidades menores iam atacando a Úmbria e a Etrúria, levou a que Umbros e Etruscos acorressem de imediato aos seus próprios territórios, abandonando Samnitas e Gauleses. Mesmo assim, a batalha de Sentino foi muito equilibrada mas em favor dos Romanos, apesar das muitas baixas, incluindo o cônsul Décio. Derrotados e sem aliados, os Samnitas apostaram numa derradeira batalha em Aquilónia, em 293, onde foram aniquilados pelo cônsul Lúcio Papírio Cursor. Os recontros do ano seguinte serviram apenas para selar o destino samnita, o que se concretizou com a tomada de Cáudio, e com a exibição e execução pública em Roma de Gávio Pôncio, comandante vencedor nas Forcas Caudinas. A partir de 290, Sâmnio passou a integrar o leque de aliados romanos, com amplas partes do seu território convertidas em terras públicas. Além das evidentes vantagens indiretas, é digno de nota o encaixe imediato, como Lívio (10.46.5-7) refere em detalhe: dois milhões quinhentos e trinta e três mil libras de aes grave, resultantes das vendas de escravos, e mil oitocentos e trinta libras de prata, saque directo dos centros urbanos.

\section{A Guerra Pírrica (280-275)}

Esta sequência de eventos colocou Roma diante das várias cidades gregas que floresceram nas costas itálicas meridionais, e que ao longo dos séculos precedentes haviam conseguido lidar com os povos nativos, e com diversas lutas internas. O início do século III corresponde, no entanto, a uma fase de enfraquecimento da Magna Grécia perante os seus vizinhos imediatos. Em 285, ou nos meses seguintes, a cidade grega de Túrio requereu proteção romana contra ataques dos Lucanos e Brútios, ambos povos falantes de Osco. Este apelo demonstra com clareza o prestígio regional da hegemonia romana nos princípios do século III. Não se conhecendo em detalhe as movimentações diplomáticas correspondentes, é certo que um tribuno da plebe recebeu uma estátua no foro a expensas gregas, e que Caio Fabrício 
Luscino conduziu em 282 uma bem-sucedida campanha terrestre em defesa de Túrio. Também fica evidente que parte do problema residia na oposição de fações locais, aristocráticas e democráticas ${ }^{14}$, e que algumas destas últimas eram antirromanas e porventura mais próximas da sua própria rival Tarento. O modesto apoio naval ao exército de Fabrício acabaria por provocar um incidente sério com Tarento, violando um tratado que impedia os navios de guerra romanos de ultrapassarem o promontório de Crotona. O resultado imediato foi a destruição ou captura da frota romana, dando assim início a um novo conflito de grandes dimensões. O facto de Tarento também ter capturado a própria Túrio, onde entretanto tinha sido estacionada uma guarnição romana, faz entrever uma justificada preocupação com a expansão de colónias, que se iam aproximando cada vez mais da área de influência grega, como é o caso de Venúsia, estabelecida em 291. A reação tarentina à presença de uma frota de guerra nas suas águas deve ser entendida neste contexto, e não, como fica representado pela analística romana, como um ataque fútil a marinheiros inocentes. Quando uma embaixada liderada por Lúcio Postúmio Megelo não conseguiu uma resposta compensatória, supostamente sofrendo as mais vis humilhações, foi conduzido um exército consular contra o novo adversário, no ano de 281 . Nos meses de entremeio, porém, os Tarentinos tinham antecipado a situação, através de pedidos de assistência entre potenciais aliados adriáticos, dirigindo-se em particular ao rei Pirro de Épiro. Um dos argumentos consistia na invocação da ascendência mítica do rei, que estabelecia uma ligação com Aquiles, e da pretensa origem troiana do povo romano, que os colocaria em campos opostos. Independentemente da efetiva força deste raciocínio, o afeto de Pirro pelos Romanos seria reduzido, e não ignorou o apelo de uma cidade aliada sob ataque iminente. A solidariedade do continente grego com as cidades na Itália era consistente e havia tido múltiplos antecedentes durante a segunda metade do século IV. Os reis Arquidamo de Esparta e Alexandre de Épiro, tio de Alexandre, o Grande, até encontraram a morte em expedições itálicas, precisamente em defesa de Tarento. Pirro, por seu turno, tinha dado provas de excelência militar, com um exército baseado

\footnotetext{
${ }^{14}$ Le Glay et al. 200967.
} 
na falange macedónica. Plutarco (Pyrrh. 15.1) descreve a sua chegada a Tarento, com vinte e três mil homens de infantaria, três mil cavaleiros, dois mil arqueiros, quinhentos fundibulários, além de vinte elefantes, números que exprimem a seriedade da iniciativa. Numa extenuante batalha nas margens do rio Síris, que se desenrolou em 280 nas proximidades de Heracleia, os Romanos saíram vencidos, tendo perdido sete mil homens, e os adversários quatro mil, embora estes constituíssem a fina-flor das tropas gregas. Em todo o caso, o efeito direto da derrota romana consistiu na aproximação a Pirro de Lucanos e Samnitas, que até então tinham observado os desenvolvimentos de longe, e que aguardavam apenas um pretexto para se rebelarem de novo contra Roma. Pirro avançou de imediato para o Lácio, onde o recrutamento de proletários ${ }^{15}$ espelha um desespero sem precedentes, antes de organizar o seu aquartelamento de inverno e de enviar para Roma o experiente emissário Cíneas, com o intuito de transmitir os termos da paz. Este tipo de procedimento diplomático, comum nas cidades orientais em sequência de uma grande derrota, incluía neste caso não apenas o respeito pela independência das cidades gregas, mas também pela autonomia de Samnitas, Lucanos e Brútios, confinando o poder romano ao Lácio, o que na prática equivalia a um recuo ao território controlado antes da Guerra Latina. A tradição, refletida por exemplo em Apiano (Sam. 10.3), pretende que o senado estaria disposto a sujeitar-se a estas condições, mas que Ápio Cláudio Cego, idoso e cego, provocou uma reviravolta nos ânimos graças a um discurso inflamado. Na realidade, o conjunto de senadores, apelidado de "assembleia de muitos reis" por Cíneas (Plu. Pyrrh. 19.5), não tinha um historial recente de submissão após derrotas, de modo que a rejeição da proposta pírrica terá conhecido contornos menos dramáticos. Nenhum dos aliados romanos se havia juntado ao lado pírrico, e nem Nápoles, nem Cápua abriram as portas, o que, sem domínio de uma grande base logística, reduziu o plano de operações a uma campanha na Apúlia ${ }^{16}$. Tendo entrementes mobilizado dois exércitos consulares, formando quatro legiões e igual número de auxiliares, os Romanos enfrentaram Pirro em Áusculo, onde combateram duas

\footnotetext{
15 Forsythe 2005, 535.

16 Bringmann 200762.
} 
batalhas em dois dias consecutivos de 279. A inicial resistência romana foi quebrada pelas falanges macedónicas e pelos elefantes, resultando na morte de seis mil homens. De acordo com as próprias memórias de Pirro, ele perdeu mais de três mil e quinhentos. É neste contexto que Plutarco (Pyrrh. 21.9) refere a famosa resposta do rei a um cumprimento pelo seu sucesso: "Se formos vitoriosos em mais uma batalha contra os Romanos, estaremos completamente arruinados".

No imediato seguimento de Áusculo aparece no porto de Óstia um comandante cartaginês de nome Mago, oferecendo o auxílio de cento e vinte navios de guerra destinados a vencer Pirro ${ }^{17}$. É verdade que se regista uma prévia atividade diplomática amistosa com Cartago, incluindo delimitações de áreas de intervenção, que implicariam provavelmente um respeito pelas ambições cartaginesas na Sicília. O acordo de 306, mencionado por Filino de Agrigento mas negado na tradição polibiana ${ }^{18}$, cuja posterior violação constitui provocação formal para a Primeira Guerra Púnica, seria disso prova. Mas fica claro que a especial disponibilidade militar de Mago se destinava mais a manter Pirro longe das costas norte-africanas, e também das sicilianas, do que a assegurar a sobrevivência de Roma. As fontes romanas pretendem que esta ajuda foi orgulhosamente recusada, mas na verdade Pirro viu-se de um momento para o outro obrigado a combater os Cartagineses no mar, e os seus aliados mamertinos em terras itálicas, o que sugere fortemente a concretização de um pacto romano-púnico que visasse as operações expedicionárias gregas. Além disso, existe uma referência direta de Diodoro (22.7.4) a um transporte de tropas romanas em navios cartagineses, com o intuito de atacar posições pírricas, tendo mesmo incendiado um depósito de madeira destinado à construção naval.

Apesar da vitória militar, o novo contexto itálico não era pois propício a Pirro, que rapidamente aproveitou um apelo das cidades gregas da Sicília para assisti-las contra os Cartagineses. Embora decifrável em termos estratégicos, na prática esta nova situação deixava os seus aliados muito vulneráveis ao recobro romano. Com efeito, entre 278

17 Forsythe 2005355.

18 Hoyos 198592 
e 275, ano do regresso episódico de Pirro, os avanços contra Brútios, Lucanos e Samnitas foram consideráveis mas obrigaram também a um desgaste generalizado, aparentemente acelerado por uma epidemia de peste. Por fim, em 275, as tropas pírricas procedentes de Tarento enfrentaram um dos exércitos consulares, sob Mânio Cúrio Dentato, que tinha sido posicionado em Malvento. Devido ao terreno muito irregular, fracassou a tentativa noturna de flanquear as posições romanas antes de amanhecer, e o destacamento foi detetado e aniquilado. O combate principal deu-se em terreno aberto, com avanços e recuos de ambas as partes. Os Romanos mataram dois elefantes e capturaram oito, que de resto viriam a constituir a apoteose do triunfo de Dentato (Plin. Nat. 8.16). Sem ter sofrido um malogro total, Pirro retirou-se em definitivo de terras itálicas, deixando apenas uma guarnição na cidade de Tarento. A despeito da sua inegável competência militar, o insucesso acompanhou-o numa sucessão de iniciativas, e viria a encontrar uma morte inglória durante uma rixa em Argos, quando um tijolo the atingiu a cabeça. O epílogo da guerra dar-se-ia em 272, quando Tarento por fim se rendeu a Roma, passando a integrar o vasto leque de aliados.

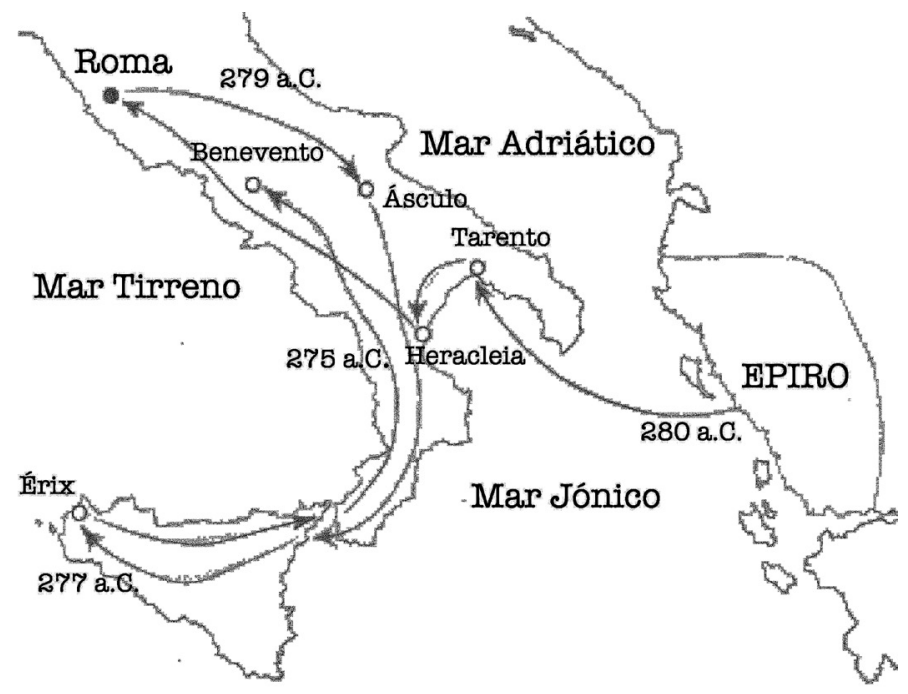

Fig. 2. Campanhas de Pirro - por Fábio Mordomo 


\section{Resultados da conquista de Itália}

A desistência de Pirro encaminhou uma poderosa mensagem a outros atores, sobretudo orientais. Dionísio de Halicarnasso (20.14) refere que o primeiro a enviar embaixadores a Roma, em 273, foi Ptolemeu II Filadelfo do Egito, que recebeu em troca uma missão de altíssima dignidade, prova da seriedade com que a política romana encarava os palcos distantes. Durante os dez anos seguintes, a inteira Itália continental foi assimilada no Estado Romano, através de operações mais ou menos complexas no Sul, em particular contra os Salentinos, mas também em zonas supostamente estabilizadas, como a Etrúria e a Úmbria. A consecutiva absorção de Estados aliados que tinham servido de tampão levou a uma espécie de efeito dominó imparável, descrito pelas fontes clássicas como um processo homogéneo que, na realidade, correspondeu a realidades distintas, contudo difíceis de aferir. Continuaram a ser instaladas diversas colónias latinas neste curto período, todas em territórios estrategicamente interessantes para Roma. Pesto e Posidónia, na Lucânia, Arímino, no acesso ao vale do Pó, Firmo, no Piceno, ou Esérnia, em Sâmnio, são disso prova clara, entre outros casos, como o de Benevento, em que se alterou o topónimo samnita Malventum para uma versão latina mais auspiciosa, precisamente na sequência da guerra pírrica. É nesta dinâmica expansionista que se entende a expedição siciliana de Ápio Cláudio Cáudice de 264, acontecimento relativamente menor no quadro geral, mas que em retrospetiva constitui o arranque formal das colossais guerras com Cartago.

O período que entremeia a Primeira Guerra Samnita, a partir de 343, e a Primeira Guerra Púnica, com início em 264, assistiu a profundas mutações militares, políticas e sociais, nas quais é muito difícil colocar uma tónica demográfica. Certo é que na primeira metade do século III conviviam na esfera romana os seus cidadãos, os seus aliados independentes, que passaram a incluir as cidades gregas, e os habitantes dos estabelecimentos coloniais latinos, que mantinham fortíssimas ligações a Roma e às comunidades de origem. Pese embora a enorme diferença de natureza e estatuto, encontravam-se todos submetidos à autoridade centralizada de Roma, e na sua organização tinham portanto pouco 
em comum com associações de inspiração helenística, que se haviam desenvolvido do lado oposto do Adriático. É importante considerar que as migrações de colonos vão a par da sucessiva criação de novas tribos romanas, fenómeno iniciado já em finais do século IV e que conduziria às trinta e cinco documentadas no fim da Primeira Guerra Púnica. Assiste-se ao mesmo tempo à captação de enormes números de escravos provenientes das guerras de conquista, que terá de alguma forma compensado a falta de mão de obra causada pelo êxodo colonial do Lácio, facilitando até mudanças na própria organização produtiva. Os números de Lívio para os primeiros anos do século III remetem para milhares de escravizados samnitas, gauleses e etruscos, entre outros, mas o mesmo Lívio menciona a lei de 357 que impõe uma taxa de cinco por cento sobre a manumissão, numa passagem provavelmente imune à invenção analística ${ }^{19}$. Isto comprova por inerência a presença regulada de escravos, em quantidades suficientes para causar legislação sobre uma pequena percentagem deles, já antes das guerras com Samnitas. A simultânea complexificação comercial de setores como a construção pública, a agricultura, a manufatura ou o transporte provocou uma incipiente amoedação, sob a forma do aes grave. E a configuração administrativa evoluiu em conformidade, primeiro com o aumento do número anual de questores, de quatro para seis, e depois através da introdução de colégios como os decemviri stlitibus iudicandis ou os tresviri capitales.

As terras confiscadas passavam a integrar o ager publicus, que cresceu em conformidade ao longo dos séculos IV e III. A sua extensão era demasiado ampla para ser integralmente destinada a colónias ou a privados. O estrategicamente importante ager Taurasinus, no centro do território samnita, só viria a ser dividido a partir de 180, e mesmo assim terá sido usado como ager scripturarius, ou área de pastagem pública arrendada, devido à geografia acentuada sem terras aráveis, que o tornava desinteressante para implantações coloniais ${ }^{20}$. É ainda muito plausível que tanto estas como a própria redistribuição de terras representaram na verdade

\footnotetext{
19 Oakley 199323.

20 Roselaar 201048.
} 
um processo muito menos traumático do que por vezes é assumido, com respeito pela propriedade privada de populações nativas ${ }^{21}$. Nesta geograficamente muito díspar Itália em vias de unificação, o fator agregante residiu acima de tudo na crescente perceção de que o benefício da submissão suplantava largamente as desvantagens associadas à perda de autonomia. O tratamento amiúde brutal de cidades reconquistadas, através de confiscações e execuções, representariam de facto um incentivo suplementar à lealdade. Mas na prática, as comunidades vencidas pelas armas acabavam incorporadas no Estado Romano, recebendo estatutos razoavelmente favoráveis, quase sempre a cidadania sem sufrágio, o que encorajava outros a preferir tratados sobre a derrota militar certa. Vantagens aliciantes eram a ausência de tributo direto, o desinteresse de Roma na gestão dos assuntos internos alheios, a participação nas guerras de conquista, e na repartição do respetivo lucro, bem como a própria conservação dos sistemas sociais em vigor. Na verdade, o senado foi defendendo sempre as aristocracias dos seus aliados, fabricando um sentimento de comunidade de dimensão itálica, e desse modo cultivou sólidas reciprocidades, como de resto se comprovaria, décadas mais tarde, perante Aníbal.

Em suma, são nitidamente estas circunstâncias da República primitiva que condicionaram os sucessos posteriores. Uma aristocracia enérgica e liderante, laços profundos entre elites e outros grupos sociais, e acima de tudo o estabelecimento e manutenção de alianças em vastos territórios conquistados são elementos tidos como fundamentais, não apenas à construção hegemónica romana, mas também às próprias origens remotas do poder imperial 22 .

\section{Tábua cronológica}

343-341 - Primeira Guerra Samnita

341 - Início da Guerra Latina

\footnotetext{
21 Terrenato 2007144.

22 Raaflaub 2007142.
} 
326 - Segunda Guerra Samnita

321 - Batalha das Forcas Caudinas

315 - Batalha de Lâutulas

305 - Batalha de Boviano

304 - Fim da "Grande Guerra" com os Samnitas

298-290 - Terceira Guerra Samnita

280-275 - Guerra com Pirro

\section{Bibliografia}

\section{Fontes primárias}

Apiano; Appian, The Foreign Wars, vol. 1, translated by Horace White, The Loeb Classical Library, Harvard University Press, Cambridge, 1912

Dionísio de Halicarnasso; Dionysius' Roman Antiquities, translated by Earnest Cary, The Loeb Classical Library vol. VII, Harvard University Press, Cambridge, 1950

Plutarco; Plutarch, The Parallel Lives, translated by Bernadotte Perrin, The Loeb Classical Library vol. IX, Harvard University Press, Cambridge, 1920

Tito Lívio; Livy IV, books VIII-X, translated by B. O. Foster, The Loeb Classical Library, Harvard University Press, Cambridge, 1963

\section{Estudos}

Bergk, A. (2011), "The development of the praetorship in the third century BC", in Beck, Hans; Duplá, Antonio; Jehne, Martin; Pina Polo, Francisco (eds.), Consuls and Res Publica: Holding High Office in the Roman Republic. Cambridge, University Press, 61-74

Bringmann, K. (2007), A History of the Roman Republic. Cambridge, Polity Press

Buck, C. D. (2005), A Grammar of Oscan and Umbrian, with a Collection of Inscriptions and a Glossary. Bristol, Evolution Pub \& Manufacturing

Chaplin, J. D. (2000), Livy's Exemplary History. Oxford, University Press

Forsythe, G. (2005), A Critical History of Early Rome, From Prehistory to the First Punic War. Berkeley/Los Angeles, University of California Press

Forsythe, G. (2011), "The Army and Centuriate organization in Early Rome", in Erdkamp, Paul (ed.), A Companian to the Roman Army. Oxford, Wiley-Blackwell, 24-41

Harris, W. V. (1985), War and Imperialism in Republican Rome: 327-70 B.C. Oxford, University Press 
Hoyos, B. D. (1985), "Treaties True and False: The Error of Philinus of Agrigentum", CQ 35 1 92-109

Le Glay, M. - Voisin, J.-L. - Le Bohec, Y. (2009), A History of Rome. Oxford, Wiley-Blackwell

Mahé-Simon, M. (2008), “Les Samnites existent-ils encore à l'époque d'Auguste?”, in Patria diversis gentibus una ? unità politica e identità etniche nell'Italia antica.

Pisa, Fondazione Niccolò Canussio, 73-87

Oakley, S. (1993), "The Roman Conquest of Italy", in J. Rich, G. Shipley (eds.), War and Society in the Roman World. London, Routledge, 9-37

Raaflaub, K. A. (2007), "Between Myth and History: Rome's Rise from Village to Empire (the Eigth Century to 264)", in N. Rosenstein, R. Morstein-Marx (eds.), A Companion to the Roman Republic. Malden/Oxford/Victoria, Blackwell Publishing, 125-146

Roselaar, S. T. (2010), Public Land in the Roman Republic, A Social and Economic History of Ager Publicus in Italy, 396-89 BC, Oxford, University Press

Rosenstein, N. (2004), Rome at War: Farms, Families, and Death in the Middle Republic. Chapel Hill, The University of North Carolina Press

Salmon, E. T. (2010), Samnium and the Samnites, Cambridge, University Press

Skutsch, O. (1985), The Annals of Q. Ennius. Oxford, Clarendon Press

Terrenato, N. (2007), "The Essential Countryside: the Roman World", in S. E. Alcock, R. Osborne (eds.), Classical Archaeology. Oxford, Blackwell Publishing, 139-161

Torelli, M. (2000), Tota Italia, Essays in the Cultural formation of Roman Italy. Oxford, University Press 